\title{
Isolated cryptophthalmia
}

INSERM

\section{Source}

INSERM. (1999). Orphanet: an online rare disease and orphan drug data base. Isolated cryptophthalmia. ORPHA:91396

Isolated cryptophtalmia is a congenital abnormality in which the eyelids are absent and skin covers the ocular bulb, which is often microphthalmic. Six cases of complete bilateral crytophthalmia have been described. Transmission is autosomal dominant. 